\title{
Do science and common wisdom collide or coincide in their understanding of relational aggression?
}

\author{
Heather S. Doyle ${ }^{1}$ and Caven S. Mcloughlin ${ }^{2 *}$ \\ ' Medina City Schools, Medina, OH, USA \\ 2 Kent State University, Kent, OH, USA
}

Edited by:

Susan M. Rivera, University of

California, USA

\section{Reviewed by:}

Susan M. Rivera, University of

California, USA

${ }^{*}$ Correspondence:

Caven S. Mcloughlin, School of Lifespan Development and Educational

Sciences, Kent State University, PO

Box 5190, Kent, OH 44242-0001, USA.

e-mail: caven@kent.edu

Relational aggression is a form of covert or indirect aggression or bullying in which harm is caused through damage to relationships or social status within a group, rather than through physical violence. We compare findings from empirical research into relational aggression with the depictions, interpretations and interventions described in trade-books and popular media dealing with that same topic. Relational aggression is more common and more studied among girls than boys and is popularly described as synonymous with "mean-girl" behaviors. We investigate the degree that popular trade books and movies accurately portray findings from researched investigations including the incidence and indicators of the condition and its remedies. We determine that there is a great deal of similarity between these two sources in how relational aggression is understood and how it may be treated. The concurrence across both dissemination formats reflects terminology and definitions, the harmful effects of relational aggression, the gender-specific nature of the condition to women and girls, its age of occurrence, the impact of parenting styles, its relationship to girls' social competence, and nature of its expression through non-physical means.

Keywords: relational aggression, indirect aggression, gender differences, popular culture, girl bullying, social aggression, relational aggression media, mean girl media, mean girl syndrome

Overt aggression is typically what comes to mind when the topic of youth violence is discussed. While the negative effects of overt aggression certainly are substantial and well-documented, there is another form of aggression with comparable potential for damage that until roughly 15 years ago has largely been overlooked (Kuppens et al., 2008). This more subtle brand of violence, known as relational aggression, often goes undetected by supervising adults precisely because it is more covert (Herrenkohl et al., 2007).

Crick and Grotpeter first introduced the topic, definition and nomenclature for relational aggression in 1995. Since then interest in the phenomenon has grown among the public and scholars alike, resulting in the production of several movies and television episodes, and hundreds of popular books and research articles devoted to the topic. Coverage by popular media sources can serve as powerful platform for topics inspiring a level of awareness and interest among the masses that scholarly literature alone cannot reach. Although the information that is provided by research articles is invaluable and perhaps the best source for guidance regarding best-practice, it is often inaccessible to the parents, educators, and practitioners in the field that most could benefit from such insight. Furthermore, empirical publications on relational aggression typically address specific facets of a topic which provides explicit information on the theme being explored, yet often fail to look at the big picture and provide practical suggestions. Popular literature offers a sampling of information on many topics associated with relational aggression therefore offering practical advice in a format that can be easily understood and applied by the lay public. Consequently, the extensive amount of popular wisdom available on the topic of relational aggression simply cannot be ignored.
The purpose of this commentary is to provide a brief overview of the extant empirical investigations about relational aggression and contrast the findings from science with a sampling of popular recent publications that feature a discussion of relational aggression. First, the components of relational aggression, its prevalence, and means of expression as identified by empirical literature in psychology/education will be presented. Next, a brief introduction to six popular-culture sources aligned to the topic of relational aggression will be provided. The article concludes with an analysis of the themes common to these empirical and popular sources and suggest how the resulting differences might be reconciled.

\section{A REVIEW OF THE EMPIRICAL LITERATURE ON RELATIONAL AGGRESSION WHAT IS RELATIONAL AGGRESSION?}

Relational aggression is defined as a brand of behavior that intentionally damages or has the potential to damage an existing relationship (Pellegrini and Roseth, 2006; Doyle and DeFago, 2009). Specifically, behaviors such as spreading lies, gossip or secrets, ignoring or "giving the silent treatment," and either directly or covertly excluding a peer from an activity all have been used to bring harm or threaten to bring harm to relationships (Crick et al., 1999; Pellegrini and Roseth, 2006; Murray-Close et al., 2007). This form of aggression may be direct (e.g., such as telling a person she is being excluded from a party) or indirect (e.g., spreading rumors about a person so that peers will reject her) (Crick et al., 2006b). Due to evidence of significant commonality in the behaviors associated with indirect aggression, indirect bullying, relational aggression and social aggression (e.g., Xie et al., 2002a,b), relational aggression 
is the term that characteristically is used to encompass all of these phenomena (Archer and Coyne, 2005; Coyne et al., 2006; Pellegrini and Roseth, 2006; Doyle and DeFago, 2009).

\section{OUTCOMES ASSOCIATED WITH RELATIONAL AGGRESSION}

Relational aggression results in significant and sometimes devastating outcomes for victims as well as for aggressors. Effects of relational aggression on victims include decreased rates of peer acceptance; lowered school achievement; and higher rates of peer rejection, internalizing symptoms, feelings of loneliness, emotional distress and drug use (Crick and Bigbee, 1998; Ostrov and Keating, 2004; Woods and Wolke, 2004; Johnson and Foster, 2005; Sullivan et al., 2006). Several studies have revealed more significant maladaptive effects for females than for males, and evidence suggests that children who display gender non-normative types of aggression (e.g., females who are physically aggressive and males who are relationally aggressive) may exhibit greater psychosocial adjustment problems than those for whom aggression is gender normative (Crick and Bigbee, 1998; Prinstein et al., 2001). For children, engagement in relational aggression has been shown over time to predict increases in social, psychological, and behavioral maladjustment, particularly internalizing and externalizing difficulties and peer rejection (Crick, 1996; Crick et al., 2006b; Werner and Grant, 2009).

\section{FEMALES AND RELATIONAL AGGRESSION}

Contemporary research indicates are that girls are more attuned to and affected by relational aggression than are boys. Relationally provoking situations (e.g., being excluded from a party) result in significantly higher levels of emotional distress for females than for males (Crick et al., 2002). Relational aggression also appears to have greater long-term effects on social adjustment in females. Crick (1996) found that teacher-reported relational aggression in girls tended to contribute to overt aggression in the prediction of future social adjustment difficulties; whereas for males, relational aggression did not contribute to overt aggression in the prediction of future social maladjustment.

Exposure to and engagement in relationally aggressive behaviors typically has been dismissed as a female rite of passage or as "girls being girls." Evidence indicates that by mothers, relationally aggressive behaviors are considered to be more acceptable than physical aggression; mothers attribute less seriousness in terms of the child's responsibility, for engaging in relationally aggressive behaviors than for overt aggression (Werner and Grant, 2009). Relational aggression typically takes place within groups of friends and each member of the group is likely to assume a different role (victim, bystander, aggressor; Sutton and Smith, 1999; Craig et al., 2000; Werner and Grant, 2009).

Crick and Grotpeter (1995), who originally described the behavior pattern, maintained that children resort to techniques that are likely to inflict the most damage to the social goals of a target whenever they intend harm to others. Boys tend to use physical forms of aggression that hinder the dominance goals of other boys, while girls use relational aggression in an attempt to hinder the goals of affiliation and intimacy that are more typical of girls (Block, 1983; Crick and Grotpeter, 1995). Furthermore, relationally aggressive acts are perceived by girls, in comparison to boys, as being more hurtful and cruel. Accordingly, girls typically experience increased levels of emotional and physiological distress when they are the recipients (Galen and Underwood, 1997; Giles and Heyman, 2005; Coyne et al., 2006; Cullerton-Sen et al., 2008). These findings support the assertion that girls tend to place greater value on relationships and perceive greater hurt when their relationships are jeopardized in comparison to boys (Coyne et al., 2006).

\section{DEVELOPMENTAL TRAJECTORY OF RELATIONAL AGGRESSION}

Children as young as 3 years of age have been described as exhibiting relationally aggressive behavior (Ostrov et al., 2005). While relational aggression is present throughout childhood, adolescence, and even into adulthood, the nature of the behaviors changes in step with cognitive and social development. Middle childhood (fourth grade; 9 years) or the late elementary school years are cited as being the period when relationally aggressive tactics become more complex and sophisticated. This feature, in tandem with the increased importance of peer acceptance and relationships which are more salient at this age, leads relational aggression to become more substantial and its consequences more damaging (Crick and Grotpeter, 1995; Rys and Bear, 1997; Crick and Dodge, 1999).

Relational aggression has been shown to be highly stable across the developmental period (Crick, 1996; Vaillancourt et al., 2003; Herrenkohl et al., 2007). Crick (1996) followed 245 children aged 9-12 years over the course of an academic year, assessing them three times using peer nomination and teacher ratings of aggression. Relational aggression was reported to be relatively stable, with correlation coefficients of 0.68 for females and 0.56 for males (Crick, 1996). Crick et al. (2006b) reported comparable results for 9- to 10-year-old children over a 1-year period, with correlations of 0.55 for boys and 0.54 for girls using peer nomination measures. Cillessen and Mayeux (2004) utilized a longitudinal design to examine the stability of relational aggression in 905 children and young adolescents aged 10-14 years. Results from peer nominations indicated that correlation coefficients across the age-range varied from 0.37 (from grade 5 to 9) to 0.75 (from grade 7 to 8 ) for females, with similar patterns evident for males (Cillessen and Mayeux, 2004). Stabilities were highest across shorter intervals and for older participants (Cillessen and Mayeux, 2004). A subsequent investigation conducted over a 7 -year period for grades 5 to 12 reported similar findings (Cillessen and Borch, 2006).

\section{SOCIAL COMPETENCE}

By comparison with overt or physical aggression, relational aggression is associated with higher levels of social intelligence (Kaukiaienen et al., 1999; Andreou, 2006). While social intelligence typically is associated with prosocial behaviors, it can be used as a tool for antisocial ends (Bjorkqvist et al., 1992; Kaukiaienen et al., 2002; Andreou, 2006). Andreou (2006) found that social skills negatively predict overt aggression, and relational aggression is positively linked with social information processing and social awareness.

Models of social information processing interpret children's social behavior as a function of skills in encoding and interpreting social cues, clarifying goals, accessing or constructing a response, deciding 
on a response and enacting a response (Crick and Dodge, 1994; Crick et al., 2002). Confirmatory research indicates that physically and relationally aggressive children interpret provoking situations differently. Relationally aggressive children have a tendency to exhibit hostile attributional biases for specifically socially provoking situations, such as being excluded from a birthday party (Crick and Grotpeter, 1995; Crick et al., 2002). Physically aggressive children are more likely to respond to instrumental provocations with anger (e.g., getting pushed by a peer; Crick et al., 2002).

\section{THE INFLUENCE OF THE SOCIAL NETWORK}

Peer groups play a significant role in the shaping of both positive and negative behavior among children. Relationships with others, according to social identity theory, play an important role in self-appraisal, which in turn motivates member of the peer group to create and maintain the norms of the group so as to achieve a positive group identity (Tarrant, 2002; Ellis and Zarbatany, 2007). This theory explains the conformity in children's and adolescents' peer groups and the development of antisocial behavior (Harris, 1995; Ellis and Zarbatany, 2007). A second factor which may explain the tendency of children and adolescents to conform to peer group norms involves group members passively falling victim to processes such as peer pressure, manipulation, and social reinforcement that are employed by others to ensure that group norms are maintained (Brown et al., 1986; Ellis and Zarbatany, 2007).

\section{THE ROLE OF PARENTS}

Several well designed studies have looked at how aspects of parenting styles relate to relational aggression. Parents can play a key role in the prevention and intervention, or, in some cases, contribute to the probability that their child will engage in relationally aggressive behaviors with peers. Investigating parenting related variables is perhaps the first step in the search for the developmental foundation of relational aggression. Broad parenting behaviors or styles have been linked to relational aggression and studies have identified unique parenting behaviors exist which may socialize relational aggression in children.

Research confirms that parental perception of relational aggression and the likelihood for parents to intervene when their children engage in such behavior may have an impact on the tendency for children to exhibit relationally aggressive behaviors. A study by Werner et al. (2006) posits that when presented with hypothetical situations involving physical and relational aggression, mothers are more likely to indicate that they would do nothing in response to relational aggression. Mothers who indicated that they would intervene reported that they would do so using methods that were significantly lower in power assertion when communicating to their child about the violation of a moral rule (Werner et al., 2006). Children of mothers who reported the higher levels of rule violation in relationally aggressive behaviors were described by their teachers as less relationally aggressive and demonstrating higher levels of prosocial behavior with peers (Werner et al., 2006). Werner and Grant (2009) have since determined that mothers who reported that they would respond with higher levels of disapproval to their daughters' relationally aggressive behavior had daughters who themselves were significantly better accepted by peers and more prosocial according to their teachers' reports. Overall, mothers in this latter study assigned less responsibility to their children when they engaged in relational aggression as compared to when they displayed physical aggression; that is, mothers evaluated relationally aggressive behavior more positively and representative of a less-serious infraction than physically aggressive behavior (Werner and Grant, 2009). Differing beliefs regarding physical and relational aggression are likely a result of the damage done by relational aggression being less visible to outsiders and the fact that children are likely to take on the roles of bystander, victim, and aggressor within the relational aggression cycle, which results in the harm being less concentrated on a single individual (Sutton and Smith, 1999; Craig et al., 2000; Bauman and Del Rio, 2006; Werner and Grant, 2009).

When looking at the influence associated with parenting styles, Bandura's Social Cognitive Theory indicates that parents who employ authoritarian strategies of parenting (which is a punitive style demanding strict adherence to rules and limits negotiation and dialog between parent and child) will raise children who behave in a similar domineering fashion toward peers (Casas et al., 2006; Sandstrom, 2007). Likewise, indulgent, laissez faire or permissive methods of parenting (characterized by a failure to set limits or boundaries and relatively few behavioral expectations of children) may result in children with egocentric tendencies who expect that peers should accommodate their needs (Sandstrom, 2007).

Hart et al. (1998) found that among a sample of Russian preschoolers more responsive parenting was linked to lower levels of relational aggression among boys and higher levels of relational aggression among girls. In a study including Chinese preschoolers a positive relationship was found to exist between mothers' use of physical coercion and physical aggression in boys (Nelson et al., 2006; Sandstrom, 2007). Additionally, the use of psychological control by mothers and fathers (which is a brand of discipline involving the withdrawal of parental love and attention as an expression of displeasure with a child's behavior to manipulate behavior of children) was positively linked to relational aggression in girls (Casas et al., 2006; Nelson et al., 2006). Maternal use of authoritarian strategies was correlated both with relational and overt aggression in Sandstrom's study conducted with fourth grade students (2007). The effects of permissive parenting were moderated by gender; resulting in a positive relationship with relational aggression in girls and no significant association for boys (Sandstrom, 2007). However, Casas et al.'s (2006) study conducted with families with preschool age children found a significant connection between mothers' permissive parenting and relational aggression among both boys and girls, suggesting that age may be a factor when considering the influence of parenting styles. A possible rationale for the link between permissive parenting and relational aggression is that as a result of this parenting style, girls enter the social world with a sense of entitlement and selfimportance which conflicts with the nature of female friendships where inter-connections and relationships are valued over personal agency (Sandstrom, 2007).

While permissive parenting is linked to female relational aggression, empathy and emotional warmth, a facet of this parenting style serves as an inhibitor to relational aggression. Barnett (1987) explains that parenting practices which foster empathy in children include those that are responsive to children's emotional needs, allow 
for expression of emotions, and encourage children's sensitivity to others. A study conducted with elementary school-aged children and their mothers confirmed this assertion finding that high levels of parental warmth and parental expression of positive emotions in the presence of the child were linked to high levels of empathy in children (Zhou et al., 2002). In turn, the absence of emotional connectedness and warmth between parent and child may lead to children engaging in bullying behaviors (which include many of the same behaviors as relational aggression). Research with several groups has indicated that high levels of maternal anger and low parent-child involvement is directly related to increased bullying behavior (e.g., Curtner-Smith, 2000; Flouri and Buchanan, 2003; Curtner-Smith et al., 2006). Bullies also report greater emotional distance between themselves and parents and more communication difficulties with parents than do non-bullies (Bowers et al., 1992; Rigby, 1994; Curtner-Smith et al., 2006). In a study differentiating between relational bullying behaviors and overt bullying behaviors, children with mothers who exhibited low levels of empathy for their children had higher scores for both overt and relational bullying when compared to children of mothers who were high in empathy (Curtner-Smith et al., 2006). The same study also found that mothers who had developmentally appropriate expectations for their children, and who valued children's independence over their own need to exert power, had children with the lowest scores for relational bullying (Curtner-Smith et al., 2006). Negative maternal affect was also found by Brown et al. (2007) to be associated with relational aggression among children ranging from 5 to 8 years of age.

\section{PERCEIVED POPULARITY AND SOCIOMETRIC POPULARITY}

Investigations into the association between relational aggression and popularity have examined two moderately correlated but nonetheless distinct constructs: Sociometric popularity and perceived popularity (Parkhurst and Hopmeyer, 1998; LaFontana and Cillessen, 2002; Lease et al., 2002). Sociometric popularity describes how well-liked a person is by their peers; it typically is measured using nominations where peers name who is most- and least-liked (Cillessen and Mayeux, 2004). Perceived popularity is an indication of an individual's social reputation and influence and is measured by means of peer identification of who is "popular" (Cillessen and Mayeux, 2004). A child who is sociometrically popular is not necessarily part of the "popular crowd;" furthermore, a child who is part of the popular crowd is not necessarily sociometrically popular. Overall, perceived popularity has been found to be more stable than sociometric popularity or social preference due to the higher level of consensus regarding reputation compared to individual liking. Finally, perceived popularity was found by Cillessen and Mayeux (2004) to be more stable among girls, and social preference was a more stable construct among boys.

Studies consistently have determined that the association between relational aggression and the two variations of popularity further differentiate the two constructs. A negative correlation has been found to exist between social preference (i.e., sociometric popularity) and both relational and physical aggression, while perceived popularity was positively correlated with both types of aggression in a study conducted with 9- to 13-year-old students (LaFontana and Cillessen, 2002). In their longitudinal study of more than 900 children in grades 5 through 9, Cillessen and Mayeux (2004) reported that relational aggression reliably and positively predicted perceived popularity in every grade. A contrastive pattern was demonstrated for social preference; relational aggression was consistently and negatively associated with this "likeability" construct, and the magnitude of this effect increased over time. Gender and age effects of these reported associations also are evident, with more striking patterns being demonstrated for females (Cillessen and Mayeux, 2004), and an age-related developmental trajectory characterized by a change in the direction of the association between relational aggression and perceived popularity between preschool/middle childhood and later adolescence (Cillessen and Mayeux, 2004; Rose et al., 2004; Cillessen and Borch, 2006; Sandstrom and Cillessen, 2006).

Peer group social status or centrality has been defined as the extent to which a peer group occupies a central location within a larger social group. Central peer groups are often very influential, and their level of influence may be enhanced by means of both prosocial and antisocial behaviors (Adler and Adler, 1995; Ellis and Zarbatany, 2007). The exclusivity of a central peer group and loyalty among its members is often maintained through relationally aggressive behaviors (Ellis and Zarbatany, 2007). In a study exploring the relationship between deviant behavior and peer group social status (defined as the degree to which a peer group occupies a central location within the larger social network), Ellis and Zarbatany (2007) found that children in centralized and highly relationally aggressive peer groups experienced an increase in relationally aggressive behavior over time. This increase did not occur for children who were in relationally aggressive, for less centralized peer groups or for physically aggressive behavior (Ellis and Zarbatany, 2007).

\section{POPULAR RESOURCES ON RELATIONAL AGGRESSION}

The popular sources cited in this article were selected for their recency, their impact (in terms of market share as determined by amazon.com rankings), and as icons for their media-types. In order for a book or movie to be selected for inclusion it must have been published within the past 10 years. The amazon.com sales ranking system was chosen as the metric for market share due to the popularity of the retailer and the reputation of its sales ranking system as a valid indicator of success for books and movies.

Perhaps the best known trade book addressing relational aggression is Queen Bees and Wannabes: Helping Your Daughter Survive Cliques, Gossip, Boyfriends, and Other Realities of Adolescence (2002) by Rosalind Wiseman. Wiseman, who established a non-profit organization that focuses on empowering teens, includes in this book research that she has conducted with teens. Addressed to parents and other adults involved with adolescent girls, Queen Bees and Wannabes shares information about the social minefields of female adolescence and the deep scarring that can result. An overview of the common patterns of aggressive teen girl behavior is provided as well as tips for helping girls deal with the pitfalls associated with their aggressive behavior.

Odd Girl Out (2002) is book authored by Rachel Simmons that addresses the "hidden culture of aggression" among adolescent girls. The idea for Odd Girl Out resulted from Simmons' own experi- 
ences as a victim of bullying and the lack of resources on social or relational aggression she when she was searching for information regarding her experiences. Discussions included in the book involve girls of all ages, and many of the victims' stories span decades which conveys how significant and influential instances of relational aggression can be to an individual.

A book for teens discussing relational aggression is Girls Against Girls: Why We Are Mean to Each Other and How We Can Change (2009) by Bonnie Burton. In the first chapter Burton describes five possible theories that could explain why girls hurt each other. Subsequent chapters outline ways in which girls are mean to each other, what to do when you are the target of others' meanness, how to get help from other sources, and how girls can stop the cycle of relational aggression. The organization and format of the book is tuned to the intended audience of adolescent girls (e.g., attention-getting headings and short paragraphs incorporating relevant quotes).

Tripping the Prom Queen: The Truth About Women and Rivalry (2006) by Susan Shapiro Barash is a book that examines the rivalry, jealousy, and competition that occurs between women of all ages. Differences between male and female rivalry and competition are explored as well as the complicated nature of female friendships and relationships. The final two chapters focus on establishing and maintaining healthy female friendships and how competition can serve as a healthy motivator. While the book clearly targets adult women, its content would be also be appropriate reading material for high school age girls.

Mean Girls Grown Up: Adult Women Who Are Still Queen Bees, Middle Bees, and Afraid-to-Bees by Dellasega (2005) addresses relational aggression that occurs in adulthood. Stories from women who have confronted "mean girls grown up" as well as those who have played the role of "queen bee" are included. Excerpts from news stories involving incidents of relational aggression abound. Generally, there are very few resources available that specifically address relational aggression among adult women; this book breaks the mold in that it explores how relational aggression occurs in a variety of situations faced by adult women.

While the most of the general public is unfamiliar with relational aggression, the meaning of the term becomes clear to most when it is referenced in conjunction with the movie Mean Girls (Messick et al., 2004). This movie, which is based on the book Queen Bees and Wannabes: Helping Your Daughter Survive Cliques, Gossip, Boyfriends, and Other Realities of Adolescence (Wiseman, 2002), introduced a mainstream audience to the relational aggression that occurs among adolescent girls. Many of the ideas discussed in Wiseman's book are referenced in the movie (Simmons, 2002; Messick et al., 2004).

\section{MAJOR THEMES APPEARING IN POPULAR LITERATURE AND THEIR CONNECTION TO RESEARCH}

In this section, the themes explored by the seven popular publications featured previously are reviewed and compared to the findings cited in the academic literature covering relational aggression. The general themes explored within each popular medium will be described. Findings of empirical research relevant to each theme will be provided in order to buttress or to challenge the commentary within the popular resource.

\section{FEMALES AND RELATIONAL AGGRESSION}

In her book Girls Against Girls: Why We Are Mean to Each Other and How We Can Change (2009), Bonnie Burton contrasts girls with boys. Girls are described as Burton as being more skilled in communication, possessing a greater awareness of their emotions and placing more value on sustained relationships with others (2009). There are also discussions related to the influence of hormones and brain development during adolescence which results in misinterpretations of social situations and drastic changes in emotions (Burton, 2009). The significance placed on the importance and enduring nature of relationships by women is well supported by research on relational aggression (Galen and Underwood, 1997; Coyne et al., 2006; Cullerton-Sen et al., 2008).

In Cheryl Dellasega's book Mean Girls Grown Up: Adult Women Who Are Still Queen Bees, Middle Bees, and Afraid-to-Bees (2005) gender differences which predispose women of all ages to relational aggression behavior patterns are discussed - including women's inclination to hold in higher regard the welfare of the group rather than individual achievement, the importance of relationships to women's self-identity, and women's ability to better interpret social cues when compared to men. These differences, which logic suggests should result in closer bonds with others, often lead to relationally aggressive behavior, which in turn damages the relationships that females yearn to form and maintain. Dellasega also elaborates on how these differences change over time making reference to the nature of men's relationships when compared to women's relationships. Women tend to form closer bonds with female friends than do men with their same-sex friends. While men often have "buddies" or "neutral" acquaintances with whom they engage in activities, women's same-sex relationships are typically more emotionally charged.

The cultural expectations regarding female behavior are explored in detail in popular literature. "Our culture refuses girls access to open conflict, and it forces their aggression into non-physical, indirect, and covert forms" (Simmons, 2002, p. 3). Girls are expected to mature into nurturing caretakers; consequently, being friendly, agreeable and "nice" is valued above all else (Simmons, 2002). Behaviors that are even mildly associated with aggression are discouraged by adults early in girls' lives (e.g., arguing, speaking loud, non-compliance; Simmons, 2002). The idea that overt aggression is discouraged among girls due to gender-related expectations and the fear of losing friendships is also addressed by Burton (2009) and is considered a possible motive for relationally aggressive behavior related to the repression of feelings of anger. The book further explains that these feelings of anger resurface often and result in girls talking to other girls about the person that upset them, which starts relationally aggressive behaviors such as a cycle of gossip and rumors throughout the social group (Burton, 2009). The empirical literature confirms that males exhibit higher rates of physical aggression when compared to females of all ages (Bjorkqvist et al., 1992; Crick and Grotpeter, 1995; Crick, 1996; Crick et al., 1997, 2006a; Crick and Bigbee, 1998; Bonica et al., 2003; Ostrov and Keating, 2004). While it could be theorized that girls are conditioned to refrain from physically aggressive behavior, there is no empirically derived evidence confirming the 
significance of such conditioning or that refraining from physically aggressive behaviors results in the expression of anger via relational aggression.

\section{POPULARITY}

In Queen Bees and Wannabes: Helping Your Daughter Survive Cliques, Gossip, Boyfriends, and Other Realities of Adolescence, Wiseman (2002) differentiates between "good" and "evil" popularity. Good popularity is described as when a girl is genuinely liked by others because she is pleasant and socially appropriate toward others. This positive variation of popularity in referred to as sociometric popularity in research literature, and is not linked to relational aggression or to maladaptive social behaviors (LaFontana and Cillessen, 2002; Cillessen and Mayeux, 2004). Wiseman explains the concept of "good popularity" by explaining that if parents could spy on their daughter who is popular in a "good" way they would be proud of how she treats other girls (2002). "Evil popularity" refers to the concept of perceived popularity, an individual's social reputation and influence, which has empirically been linked to relational aggression (Cillessen and Mayeux, 2004). When defining "evil" popularity Wiseman refers to the roles of the social clique members: Queen Bee, Sidekick, Banker, Floater, Torn Bystander, Pleaser/Wannabe/Messenger, and Target. The Queen Bee, who is considered to possess attributes of Wiseman's "evil popularity," acquires her regard through fear and control, and fits the quintessential description of a relationally aggressive girl as featured in much of the available research on the topic. "Through a combination of charisma, force, money, looks, will and manipulation, this girl reigns supreme over the other girls and weakens their friendships with others, thereby strengthening her own power and influence" (Wiseman, 2002, p. 25). Dellasega also categorizes adult females as Queen Bees, Middle Bees, or Afraid-to-Bees based on their behavior and even provides a self-quiz to help the curious reader identify to which group they may belong (2005). The description in this text of the behavioral inventory exhibited by the Queen Bee is entirely consistent with what most researchers describe as relationally aggressive behavior.

\section{SOCIAL NETWORKS}

A clique is defined as a "narrow exclusive group of persons; especially one held together by common interests, views, or purposes" (Merriam-Webster, 2009, definition). Wiseman states that cliques act most detrimentally in sixth, seventh and eighth grades (2002). The research on relational aggression and popularity indicates in parallel that cliques or peer groups typically become more of an influential factor during the middle school years. In Mean Girls Grown Up, Dellasega asserts that cliques certainly do not disappear in adulthood; they just become more complex and differentiated with cliques centered at work, at church, within extended families, and even in the PTO or other organizations in which women dominate (2005). It is natural for cliques to occur in all settings and stages of life; however, high levels of exclusivity in cliques prompt members to use relationally aggressive tactics to further the values, norms and status of the group. Crick and Grotpeter (1995) found that the friendships of relationally aggressive children were characterized by greater intimacy. Additionally, teacher ratings in a study conducted by Sebanc (2003) indicated that children's friendship exclusivity and intimacy were positively correlated to relational aggression.

While gossiping is not a topic that is specifically addressed in extant empirical literature on relational aggression, it is certainly a relevant theme among adolescent girls and is included in the majority of definitions of relationally aggressive behavior. Gossiping is addressed by Wiseman in Queen Bees and Wannabes (2002) in a manner that encourages parents to recognize that gossip is a reality and, further, the book provides caretakers with advice on how best to handle situations where their daughter is the one talking or being talked about (2002). Burton's (2009) book, Girls Against Girls, maintains that while gossip itself may serve as a bonding activity for girls to gain acceptance among their peers it can also be malicious in intent.

\section{PARENTING}

The topic of parenting is also addressed in the popular literature on relational aggression. Wiseman's Queen Bees and Wannabes (2002) provides descriptions of parenting styles almost wholly parallel to those identified by empirical researchers. She encourages an authoritative parenting style as well as provides advice to parents on how best to encourage open communication. The major motion picture Mean Girls also provides an accurate portrayal of the permissive parenting style that researchers have linked with relational aggression in children. For example, the mother of Regina George, who is the "Queen Bee" of the clique featured in the movie, is depicted as a permissive mother who offers to let Regina and her friends drink alcohol at her house. While Burton (Girls Against Girls, 2009) does not specifically refer to the nomenclature for parenting styles, she does convey that girls may learn to be cruel to one another from older women who have been similarly treated (2009). This link between parental relational aggression and the use of psychological control tactics and authoritarian strategies among parents is well-documented in research.

\section{RIVALRY}

Adult female rivalry is a topic covered by Barash (2006) in Tripping the Prom Queen: The Truth About Women and Rivalry. This book outlines the interviews that Barash completed with 500 women from a variety of backgrounds regarding woman-to-woman rivalry. She reports that women are so concerned with competing against other women that they avoid certain social functions in order avoid such rivalry. Results of her interviews revealed that women are willing to "cut each other's throats" to obtain jobs, partners, and social approval (Barash, 2006). She reports that nearly $90 \%$ of women claim that envy or jealousy toward other women affects their lives in some way; while $80 \%$ of women say they have been a target of jealousy displayed by other women. Stories of women's rivalry in various situations (e.g., the office, dating and charity involvement) are recounted by Barash with analytical commentary regarding the relevance of each anecdote. Barash states that women seem to compete with other women throughout their lifespan. While the theme of the rivalry changes according to age (i.e., 15-year-olds may compete over clothes or boys, while 75-year-old women may compete over the accomplishments of their grandchildren). 
Differences between male and female rivalry is also discussed in Tripping the Prom Queen (Barash, 2006). Males are often thought of as the more competitive gender since they are cultured from a young age to believe that winning is most important and, also, since as a gender group they have greater direct involvement in sports. One of the main gender differences, it is explained, is that females compete primarily with other females. Barash explains that women often feel that there is nothing they can do about the success of men. Also, when women are successful other women regularly respond with envy and jealousy; however, when a woman fails, other women are there to comfort her. While the empirical research literature does not imply that women are significantly more predisposed to engage in unhealthy levels of competition or rivalry, some evidence exists that individuals who have relationally aggressive tendencies are more likely to engage in rivalry or to interpret situations as being oppositional. Crick and Grotpeter (1995) and Crick et al. (2002) found that relationally aggressive children have a tendency to exhibit hostile attributional biases for socially provoking situations. Thus, individuals who have relationally aggressive tendencies may interpret as a personal threat situations such as a coworker getting a promotion or an acquaintance getting married.

\section{SUMMARY/CONCLUSIONS}

This review of popular and research literature has identified several themes about relational aggression that appear in both dissemination formats. In some cases the information presented by popular resources is in accord with the research on relational aggression; however, in other cases, disparity exists between what popular culture and science tells us about relational aggression. The following synopsis and table delineate the major themes explored in literature on relational aggression and the stance taken by each of popular culture and by science.

\section{DEFINITION OF RELATIONAL AGGRESSION}

Defining the construct of relational aggression and distinguishing it from other related terms (e.g., social aggression, indirect aggression, etc.) has proven to be a challenge and is a topic of debate in the world of science for years. What discriminates relational aggression from other related forms of aggression is that damage is focused on relationships in order to harm an individual (Crick et al., 1999; Pellegrini and Roseth, 2006; Murray-Close et al., 2007). Definitions in both popular and research literature include this element of damage to relationships as the hallmark feature of relational aggression.

\section{EFFECTS OF RELATIONAL AGGRESSION}

Science and popular culture both maintain that victims of relational aggression suffer serious consequences. While research literature has established that significant outcomes are endured by both victims of relational aggression and the perpetrators, popular literature focuses predominantly on the negative effects of relational aggression on victims.

\section{FEMALES AND RELATIONAL AGGRESSION}

Nearly all of the empirical literature and popular treatises on the topic focus on females. While relational aggression certainly occurs in males, science and popular culture have noted and investigated its occurrence among females, perhaps because the effects on females are far more profound and wide-reaching.

\section{AGES OF OCCURRENCE}

While relational aggression can start as early in life as preschool and continues throughout the life span, both science and popular publications focus on its occurrence in adolescence. Some popular books have explored relational aggression taking place in adulthood, but there is very little empirical research available for this age-group. There is, however, research on relational aggression occurring among preschool age children, but popular literature for the most part does not mention young children.

\section{PARENTING}

Both science and popular culture recognize that certain parenting styles (i.e., authoritarian and permissive) are positively associated with relational aggression in children. There is also widespread acknowledgment that parents' awareness of relational aggression is negatively linked to its occurrence in children. The connection between relational aggression and parenting is likely the reason why so many books on the topic are targeted to parents.

\section{POPULARITY}

"Good-" and "bad-popularity" (also known as sociometric and perceived popularity, respectively) are discussed in popular and empirical literature, and both publication formats indicate that those who engage in relational aggression are more likely to possess perceived popularity (i.e., "bad popularity") rather than sociometric popularity, which is often gained as a results of being well-liked by peers.

\section{RIVALRY}

Popular culture depicts females as competing with each other in a variety of domains and settings to a greater degree than males (e.g., work, school, clothes, physical appearance, etc.). Empirical literature on relational aggression, however, does not clearly recognize a greater inclination toward rivalry in women compared to men. Females who engage in relational aggression may be more likely to pinpoint shortcomings in other in an attempt to damage their reputation, but there is no clear-cut evidence suggesting that one gender-group is more competitive than the other.

\section{SOCIAL COMPETENCE}

Research has linked relational aggression with higher levels of social insight and intelligence. There is also research suggesting that children who are relationally aggressive tend to interpret potentially provoking situations in a hostile manner. While social competence has been covered rather thoroughly in the empirical literature, the connection between social competence and relational aggression is not a topic that is addressed in detail in popular literature.

\section{PHYSICAL AGGRESSION}

Researchers have found that physical aggression and relational aggression are interdependent $\sim$ meaning that a child who engages in relational aggression may be more likely to engage in physical aggression, and vice versa. Popular media may mention physically aggressive behaviors as examples of relational aggression, but the association between relational aggression and physical aggression has yet to be developed as an area of focus. 
Theme

Definition of relational

aggression

Effects of relational

aggression

Females and relational

aggression

Age of occurrence

Parenting

Popularity

Rivalry

Social competence

Physical aggression
The damage directed at relationships in order to cause harm is what distinguishes relational aggression from other forms of aggression Significant negative, pervasive, and long-lasting outcomes are endured by victims of relational aggression

That males engage in relational aggression is recognized; however, because of their increased susceptibility to negative effects females are the focus of evidence-based research

Relational aggression occurs as early as preschool, but adolescence is primarily the age when relational aggression is most prominent Specific parenting styles and parental awareness of relational aggression have been associated with occurrence of the behavior

Relational aggression has been positively linked to perceived popularity and negatively linked to sociometric popularity

While hostile attributional bias has been cited in research, rivalry is not addressed in the empirical literature on relational aggression

Higher levels of social intelligence and processing skills have been determined as positively associated with relational aggression Physical aggression and relational aggression have been found to be positively correlated
Popular wisdom

The definition of relational aggression mirrors that established by research

The focus is on effects of relational aggression on victims

Females are the hub of nearly all popular literature on relational aggression. There is also speculative discussion of why females are more susceptible to relational aggression

Popular media focuses on relational aggression occurring primarily in adolescence and adulthood

The targeted audience of most popular resources is parents. Wiseman (2002) has acknowledged parenting styles that are associated with relational aggression The relationship between the two brands of popularity and relational aggression is discussed. Sociometric and perceived popularity are respectively referred to as "good" and "evil" popularity

Rivalry and competition between females is addressed in many of the popular media sources. In many cases it is referenced as being a trigger for relational aggression The connection between social competence and relational aggression is not a topic discussed in trade literature Physical aggression is usually not specifically discussed, but it may be referred to as being an example of relationally aggressive or bullying behaviors

\section{FINAL COMMENTARY}

A common thread in all the publications and media describing relational aggression, whether popular or research-based, is the significance of the event in the lives of women. While empirical and popular resources focus on relational aggression occurring at specific ages, the heart-rending stories from adults regarding incidents from their childhood and adolescence poignantly illustrate the importance of relationships in the lives of females and how much it hurts occurs when relationships are damaged. Those who are targets of relational aggression endure significant and sometimes devastating outcomes, including reduced rates of peer acceptance; stunted school achievement; and higher rates of peer rejection, internalizing symptoms, feelings of loneliness, and emotional distress (Crick and Bigbee, 1998; Ostrov and Keating, 2004; Woods and Wolke, 2004; Johnson and Foster, 2005). Further, for those who experience the adjustment

\section{REFERENCES}

Adler, P.A., and Adler, P. (1995). Dynamics of inclusion and exclusion in preadolescent cliques. Soc. Psychol. Q. $58,145-162$.

Andreou, E. (2006). Social preference, perceived popularity, and social intelligence: relations to overt and relational aggression. Sch. Psychol. Int. 27, 339-351.

Archer, J., and Coyne, S. (2005). An integrated review of indirect, relational, and social aggression. Pers. Soc. Psychol. Rev. 9, 212-230.

Barash, S. S. (2006). Tripping the Prom Queen: The Truth About Women and Rivalry. New York: St. Martin's Press.

Barnett,M.A.(1987). "Empathyand related responses in children," in Empathy and its Development: Cambridge Studies in Social and Emotional Development, eds N. Eisenberg and J. Stayer (New York: Cambridge University Press), 146-162.

problems consequent on being victimized by relational aggression, research predicts the internalizing outcomes of depression, anxiety, loneliness, isolation, and withdrawal (Crick and Grotpeter, 1995; Crick et al., 2006b). These are all serious outcomes and it is beneficial for both research and for popular trade-publications to provide accurate and contemporary descriptions of the conditions that can lead to dangerous mental health concerns. If research-based publications are the goldstandard for accuracy against which popular outlets may be measured, then it is clear that popular literature adequately and accurately portrays relational aggression.

We trust that the increased awareness of relational aggression that inevitably results from the widespread dissemination by popular literature of information on the topic will help girls and women of all ages to avoid hurtful, relationship-injuring behaviors, and build healthy, supportive relationships with one another.

Bauman, S., and Del Rio, A. (2006). Preservice teachers' responses to bullying: comparing physical, verbal, and relational bullying.J. Educ. Psychol. 98 219-231.

Bjorkqvist, K., Lagerspetz, K. M., and Kaukiainen, A. (1992). Do girls manipulate boys and fight? Developmental trends in regard to direct and indirect aggression. Aggress. Behav. 18, 117-127.

Block, J. H. (1983). Differential premises arising from differential socialization of the sexes: some conjectures. Child Dev. 54, 1335-1354.

Bonica, C.,Arnold, D.H., Fisher,P.H.,Zeljo, A., and Yershova, K. (2003). Relational aggression, relational victimization, and language development in preschoolers. Soc. Dev. 12, 551-562.

Bowers, L., Smith, P. K., and Binney, V. (1992). Cohesion and power in the families of children involved in bully/ victim problems at school. J. Fam. Ther. 14, 371-387. 
Brown, B. B., Clasen, D. R., and Eicher, S. A. (1986). Perceptions of peer pressure, peer conformity dispositions, and self-reported behavior among adolescents. Dev. Psychol. 22, 521-530.

Brown, S. A., Arnold, D. H., Dobbs, J., and Doctoroff, G. L. (2007). Parenting predictors of relational aggression among Puerto Rican and European American school-age children. Early Child. Res. Q. 22, 147-159.

Burton, B. (2009). Girls Against Girls: Why We Are Mean to Each Other and How We Can Change. San Francisco, CA: Zest Books.

Casas, J. F., Weigel, S. M., Crick, N. R., Ostrov, J. M., Woods, K. E., Yeh, E. A J., and Huddleston-Casas, C. (2006). Early parenting and children's relational and physical aggression in the preschool and home contexts. J. Appl. Dev. Psychol. 27, 209-227.

Cillessen, A. H. N., and Borch, C. (2006). Developmental trajectories of adolescent popularity: a growth curve modeling analysis. J. Adolesc. 29, 935-959.

Cillessen, A. H. N., and Mayeux, L. (2004). From censure to reinforcement: developmental changes in the association between aggression and social status. Child Dev. 75, 147-163.

Coyne, S., Archer, J., and Eslea, M. (2006). "We're not friends anymore! Unless...": the frequency and harmfulness of indirect, relational, and social aggression. Aggress. Behav. 32, 294-307.

Craig, W M., Pepler, D., and Atlas, R. (2000). Observations of bullying in the playground and in the classroom. Sch. Psychol. Int. 21, 22-36.

Crick, N. R. (1996). The role of overt aggression, relational aggression, and prosocial behavior in the prediction of children's future social adjustment. Child Dev. 67, 2317-2327.

Crick, N. R., and Bigbee, M. A. (1998). Relational and overt forms of peer victimization: a multi-informant approach. J. Consult. Clin. Psychol. 66, 337-347.

Crick, N. R., Casas, J. F., and Mosher, M. (1997). Relational and overt aggression in preschool. Dev. Psychol. 33, 579-588.

Crick, N. R., and Dodge, K. A. (1994). A review and reformulation of social information processing mechanisms in children's social adjustment. Psychol. Bull. 115, 74-101.

Crick, N. R., and Dodge, K. A. (1999). 'Superiority' is in the eye of the beholder: a comment on Sutton, Smith, and Swettenham. Soc. Dev. 8 , 128-131.

Crick, N. R., and Grotpeter, J. K. (1995). Relational aggression, gender, and social-psychological adjustment. Child Dev. 66, 710-722.

Crick, N. R., Grotpeter, J. K., and Bigbee, M. A. (2002). Relationally and physically aggressive children intent attributions and feelings of distress for relational and instrumental peer provocations. Child Dev. 73, 1134-1142.

Crick, N. R., Ostrov, J. M., Burr, J. E. Cullerton-Sen, C., Jansen-Yeh, E., and Ralston, P. (2006a). A longitudinal study of relational and physical aggression in preschool. J. Appl. Dev. Psychol. 27, 254-268.

Crick, N. R., Ostrov, J. M., and Werner, N.E. (2006b). A longitudinal study of relational aggression, physical aggression, and children's social-psychological adjustment. J. Abnorm. Child. Psychol. 34, 131-142.

Crick, N. R., Werner, N. E., Casas, J. F., O’Brien, K. M., Nelson, D. A., Grotpeter, J. K., and Markon, K. (1999). "Childhood aggression and gender: a new look at an old problem," in Nebraska Symposium on Motivation, Vol. 45, Gender and Motivation, ed. D. Bertstein (Lincoln: University of Nebraska Press), 75-141.

Cullerton-Sen, C., Cassidy, A. R., MurrayClose, D., Cicchetti, D., Crick, N. R., and Rogosch, F. A. (2008). Childhood maltreatment and the development of relational and physical aggression: the importance of a gender-informed approach. Child Dev. 79, 1736-1751.

Curtner-Smith,M.E. (2000). Mechanisms by which family processes contribute to school-age boys' bullying. Child Study J. 30, 169-186.

Curtner-Smith, M. E., Culp, A. M., Culp, R., Scheib, C., Owen, K., Tilley, A., Murphy, M., Parkman, L., and Coleman, P. W. (2006). Mothers' parenting and young economically disadvantaged children's relational and overt bullying. J. Child. Fam. Stud. 15, 181-193.

Dellasega, C. (2005). Mean Girls Grown Up: Adult Women Who Are Still Queen Bees, Middle Bees, and Afraid-to-Bees. Hoboken, NJ: John Wiley \& Sons.

Doyle, H. S., and DeFago, J. (2009). Relational aggression and child outcomes. Ohio Sch. Psychol. 54, 1-12.

Ellis, W.E., and Zarbatany, L. (2007). Peer group status and a moderator of group influence on children's deviant, aggressive, and prosocial behavior. Child Dev. 78, 1240-1254.

Flouri, E., and Buchanan, A. (2003). The role of mother involvement and father involvement in adolescent bullying behavior. J. Interpers. Violence 18, 634-644.

Galen, B. R., and Underwood, M. K. (1997). A developmental investigation of social aggression among children. Dev. Psychol. 33, 589-600.

Giles, J. W., and Heyman, G. D. (2005). Young children's beliefs about the relationship between gender and aggressive behavior. Child Dev. 76, 107-121.

Harris, J. R. (1995). Where is the child's environment? A group socialization theory of development. Psychol. Rev. 102, 458-489.

Hart, C. H., Nelson, D. A., Robinson, C. C. Olsen, S. F., and McNeilly-Choque, M. K. (1998). Overt and relational aggression in Russian nursery-school-age children: parenting style and marital linkages. Dev. Psychol. 34, 687-697.

Herrenkohl, T.I., McMorris, B. J., Catalano, R. F., Abbott, R.D., Hemphill, S.A., and Toumbourou, J.W. (2007). Risk factors for violence and relational aggression in adolescence. J. Interpers. Violence 22, 386-405.

Johnson, D. R., and Foster, S. L. (2005) The relationship between relational aggression in kindergarten children and friendship stability, mutuality, and peer liking. Early Educ. Dev. 16, 141-160.

Kaukiaienen, A., Bjorkqvist, K., Lagerspetz, K., Osterman, K., Salmivalli, C. Rothberg, S., and Ahlbom, A. (1999). The relationships between social intelligence, empathy and three types of aggression. Aggress. Behav. 25, 81-89.

Kaukiaienen,A., Salmivalli, C., Lagerspetz, K., Tamminen, M., Vauras, M., Maki, H., and Poskiparta, E. (2002). Learning difficulties, social intelligence and self-concept: connections to bullyvictim problems. Scand. J. Psychol. 43, 269-278.

Kuppens, S., Grietens, H., Onghena, P. Michiels, D., and Subramanian, S. V. (2008). Individual and classroom variables associated with relational aggression in elementary-school aged children: a multilevel analysis. J. Sch. Psychol. 46, 639-660.

LaFontana, K. M., and Cillessen, A. H. N. (2002).Children's perceptions of popular and unpopular peers: a multimethod assessment. Dev. Psychol. 38 635-647.

Lease, A. M., Kennedy, C.A., and Axelrod, J. L. (2002). Children's social constructions of popularity. Soc. Dev. 11, 87-109.

Messick, J. S., Michaels, L., Rosner, L. (Producers), and Waters, M. S. (Director) (2004). Mean Girls [Motion Picture]. Hollywood, CA: Paramount Pictures.

Murray-Close, D., Ostrov, J.M., and Crick, N. R. (2007). A short-term longitudinal study of growth of relational aggression during middle childhood: associations with gender, friendship intimacy, and internalizing problems. Dev. Psychopathol. 19, 187-203.

Nelson, D. A., Hart, C. H., Yang, C., Olsen, J.A., and Jin, S. (2006). Aversive parenting in china: associations with child physical and relational aggression. Child Dev. 77, 554-572.

Ostrov, J. M., Crick, N. R., and Keating, C. F. (2005). Gender biased perceptions of preschoolers' behavior: how much is aggression and prosocial behavior in the eye of the beholder? Sex Roles 52, 393-398.

Ostrov, J. M., and Keating, C. F. (2004). Gender differences in preschool aggression during free play and structured interactions: an observational study. Soc. Dev. 13, 255-277.

Parkhurst, J. T., and Hopmeyer, A. (1998). Sociometric popularity and peer-perceived popularity: two distinct dimensions of peer status. J. Early Adolesc. 18, 125-144.

Pellegrini, A. D., and Roseth, C. (2006). Relational aggression and relationships in preschoolers: a discussion of methods, gender differences, and function. J. Appl. Dev. Psychol. 27, 269-276.

Prinstein, M. J., Boergers, J., and Vernberg, E. M. (2001). Overt and relational aggression in adolescents: socialemotional adjustment of aggressors and victims. J. Clin. Child. Psychol. 30, 479-491.

Rigby, K. (1994). Psychosocial functioning in families of Australian adolescent schoolchildren involved in bully/victim problems. J. Fam. Ther. 16, 173-189.

Rose, A. J., Swenson, L. P., and Waller, E. M. (2004). Overt and relational aggression and perceived popularity: developmental differences in concurrent and prospective relations. Dev. Psychol. 40, 378-387.

Rys, G.S., and Bear, G.G. (1997). Relational aggression and peer relations: gender and developmental issues. Merrill Palmer Q. 43, 87.

Sandstrom, J. J., and Cillessen, A. H. N. (2006). Likeable versus popular: distinct implications for adolescent adjustment. Int. J. Behav. Dev. 30, 305-314.

Sandstrom, M. J. (2007). A link between mothers' disciplinary strategies and children's relational aggression. $\mathrm{Br}$. J. Dev. Psychol. 25, 399-407.

Sebanc, A. M. (2003). The friendship features of preschool children: links with prosocial behavior and aggression. Soc. Dev. 12, 249-268.

Simmons, R. (2002). Odd Girl Out: The Hidden Culture of Aggression in Girls. New York: Harcourt.

Sullivan, T.N., Farrell,A. D., and Kliewer, W. (2006). Peer victimization in early ado- 
lescence: association between physical and relational victimization and drug use, aggression, and delinquent behaviors among urban middle school students. Dev. Psychopathol. 18, 119-137.

Sutton, J., and Smith, P. K. (1999). Bullying as a group process: an adaptation of the participant role approach. Aggress. Behav. 25, 97-111.

Tarrant, M. (2002). Adolescent peer groups and social identity. Soc. Dev. $11,110-123$.

Vaillancourt, T., Brendgen, M., Boivin, M., and Tremblay, R. E. (2003). A longitudinal confirmatory factor analysis of indirect and physical aggression: evidence of two factors over time. Child Dev. 74, 1628-1638.

Werner, N. E., and Grant, S. (2009). Mothers' cognitions about relational aggression: associations with discipline responses, children's normative beliefs, and peer competence. Soc. Dev. 18, 77-98.

Werner, N. E., Senich, S., and Przepyszny, K. (2006). Mothers' responses to preschoolers' relational and physical aggression. J. Appl. Dev. Psychol. 27, 193-208.

Wiseman, R. (2002). Queen Bees and Wannabes: Helping your Daughter Survive Cliques, Gossip, Boyfriends, and Other Realities of Adolescence. New York: Crown Publishers.

Woods, S., and Wolke, D. (2004). Direct and relational bullying among primary school children and academic achievement. J. Sch. Psychol. 42, 135-155.

Xie, H., Cairns, R. B., and Cairns, B. D. (2002a). The development of social aggression and physical aggression: a narrative analysis of interpersonal conflicts. Aggress. Behav. 28, 341-355.

Xie, H., Swift, D. J., Cairns, B. D., and Cairns, R. B. (2002b). Aggressive behaviors in social interaction and developmental adaptation: a narrative analysis of interpersonal conflicts during early adolescence. Soc. Dev. 11, 205-224.

Zhou, Q., Eisenberg, N.,Losoya, S.H., Fabes, R., Reiser, M., Guthrie, I. K., Murphy, B.C., Cumberland, A. J., and Shepard, S. A. (2002). The relations of parental warmth and positive expressiveness to children's empathy-related responding and social functioning: a longitudinal study. Child Dev. 73, 893-915.

Conflict of Interest Statement: The authors declare that the research was conducted in the absence of any commercial or financial relationships that could be construed as a potential conflict of interest.

Received: 16 April 2010; accepted: 08 October 2010; published online: 06 December 2010.

Citation: Doyle HS and Mcloughlin CS (2010) Do science and common wisdom collide or coincide in their understanding of relational aggression? Front. Psychology 1:179. doi: 10.3389/fpsyg.2010.00179

This article was submitted to Frontiers in Developmental Psychology, a specialty of Frontiers in Psychology.

Copyright $(2010$ Doyleand Mcloughlin. This is an open-access article subject to an exclusive license agreement between the authors and the Frontiers Research Foundation, which permits unrestricted use, distribution, and reproduction in any medium, provided the original authors and source are credited. 